\title{
Prevenção e enfrentamento do bullying: o papel de professores
}

\author{
Jorge Luiz da Silva* \\ Marina Rezende Bazon**
}

\section{Resumo}

A boa convivência entre os estudantes no ambiente escolar representa um desafio. Como na escola o pluralismo da sociedade é refletido, as diferenças pessoais, étnicas/ culturais e econômicas podem originar conflitos e violência. A violência entre pares, intencional, repetitiva, que envolve desequilíbrio de poder, é denominada bullying. A escola é o local principal de expressão desta problemática que, no Brasil, ocorre com maior frequência nas salas de aula. $\mathrm{O}$ bullying afeta negativamente o clima escolar e o desenvolvimento de todos os envolvidos - agressor, vítima e espectadores. Embora o nível de conhecimento dos professores sobre o bullying varie em termos de abrangência e de profundidade, este não é, de modo geral, suficiente para que identifiquem ou para que sejam sensíveis a todas as agressóes em sala de aula. Dentro disso, as intervençôes que realizam tendem a ser pontuais e desarticuladas. Para muitos professores e outros agentes escolares prevalece a crença de que o bullying é "brincadeira" de crianças/adolescentes e de que as suas consequências não são muito graves. Assim, denota-se a importância de formação do professor, de modo a incrementar não somente seu conhecimento sobre o tema, mas, principalmente, sua sensibilidade e sua competência para intervir no problema, contribuindo assim para que o clima escolar seja menos violento e excludente. Esse é o foco deste ensaio teórico.

Palavras-chave: Bullying; Formação do professor; Intervenção.

* Mestre em Psicologia pela Universidade de Saão Paulo, Ribeirão Preto, São Paulo, Brasil.

** Professora doutora da Universidade de São Paulo, Ribeirão Preto, São Paulo, Brasil. 


\section{Bullying prevention and coping: the role of teachers}

\section{Abstract}

Satisfactory coexistence among students in the school environment is a challenge. Because schools reflect the pluralism found in society, personal, ethnic/cultural, and economic differences may lead to conflicts and violence. The intentional and repetitive violence among peers involving an imbalance of power is called bullying. The school is the place where this problem is most frequently expressed and in Brazil its occurrence is greater in classrooms. Bullying negatively affects the school ambience and the development of all those concerned - aggressor, victim and bystanders. Although teachers' level of knowledge about bullying varies in scope and depth, it is generally not sufficient for them to identify or be sensitive to any aggression in the classroom. Within this, the interventions they performed tended to be punctual andnon-articulated. For many teachers and other school agents the prevailing belief is that bullying is a "joke" of children/adolescents and its consequences are not very serious. Therefore, it is important to train teachers to improve not only their knowledge regarding the problem, but mainly their sensitivity and competence to intervene, contributing to the school ambience being less violent and exclusionary. This is the focus of this theoretical essay.

Keywords: Bullying; Teacher formation; Intervention.

\section{Introdução}

A boa convivência no ambiente escolar representa um desafio, pois, como na escola se reflete o pluralismo da sociedade, as diferenças pessoais, étnicas/culturais e econômicas podem originar conflitos. Neste contexto, as interaçóes entre os estudantes podem ser problemáticas e até mesmo violentas. A violência entre pares, intencional e repetitiva, envolvendo desequilíbrio de poder entre vítimas e agressores denomina-se bullying (SILVA et al., 2016; OLWEUS, 2013). No bullying, as agressões praticadas podem ser de natureza física (por exemplo: bater, chutar e empurrar), verbal (por exemplo: apelidar, xingar e rir) ou relacional (por exemplo: isolar socialmente a vítima, espalhar boatos e manipular relacionamentos) (SAMPAIO, 2015; OLWEUS, 2013). Trata-se de um fenômeno que pode ocorrer em diferentes locais, embora a escola seja o local privilegiado de sua expressão (SILVA et al., 2013).

A prevalência de bullying nas escolas brasileiras, no ano de 2015, identificada em uma pesquisa com amostra nacional representativa, foi de 28\% (OLIVEIRA et al., 2016). Em comparação às taxas de outros países, esta é considerada elevada. A título de exemplo, na Suécia a taxa estimada foi de 9,7\%, em Israel 15,1\%, na Espanha 17,4\%, na Itália 19,6\% e nos Estados Unidos foi de 24,5\% (DUE et al., 2009). Existem evidências de que o bullying afeta negativamente o clima escolar e o desenvolvimento de todos os envolvidos em sua dinâmica - vítimas, agressores e testemunhas. Especificamente, encontram-se a ele associados: depressão, ansiedade, insegurança, solidão, dificuldade de aprendizagem, delinquência juvenil e suicídio (OLIVEIRA et al., 2016; SILVA; BAZON, 2014; BAUMAN; DEL RIO, 2006). 
Sua magnitude e os efeitos negativos que produz impóem a necessidade de desenvolvimento de intervençóes objetivando preveni-lo ou reduzi-lo no ambiente escolar, considerando que, nessas, a participação dos professores é fundamental (TREVISOL; CAMPOS, 2016; SILVA et al., 2014). Em razão do tempo em sala de aula, os professores estáo mais próximos dos estudantes e, assim, se encontram em posição privilegiada para observarem as interaçôes, identificarem as diferentes formas de socialização entre as crianças e os adolescentes e intervirem em situações de violência que possam ocorrer, com vistas a promover relaçóes interpessoais positivas (TROOP-GORDON; LADD, 2015). É importante sublinhar que, no Brasil, diferentemente de outros países, o bullying ocorre com maior frequência justamente nas salas de aula, deduzindo-se daí que a sua manifestação ocorre, em boa parte, diante dos professores (SILVA et al., 2013). Esta situação, além de possibilitar aos mesmos a realização de açóes diretas e imediatas, implica uma maior responsabilidade deles frente ao fenômeno.

Sabe-se que os esforços dos professores para reduzir o bullying, em sala de aula, têm, na maioria das vezes, resultados positivos (TTOFI; FARRINGTON, 2011). Por exemplo, Smith; Pepler e Rigby (2004) identificaram, em sua pesquisa, que quando os estudantes contam a alguém sobre a sua condição de vítima, em $67 \%$ das vezes eles deixam de ser agredidos, se há respostas imediatas, coerentes e eficazes da parte de quem recebe a informação, especialmente se esta pessoa for um dos professores. Devido à diferença de poder (em termos físicos e/ou psicológicos) entre vítimas e agressores, é importante que as vítimas recebam apoio dos colegas e, principalmente, dos professores e demais agentes escolares, pois elas não possuem as condiçóes para se autodefenderem, sendo que, muitas vezes, suas reaçôes ao agressor agravam as açóes deste, pois funcionam como reforço negativo e/ou positivo ao bullying (SILVA et al., 2016). Considerando a legítima autoridade que possuem, os professores têm responsabilidade de intervir nessas situaçóes e devem estar preparados para fazê-lo adequadamente, de modo a darem fim às agressôes que presenciam ou lhes são relatadas (TROOP-GORDON; LADD, 2015).

Entretanto, nem sempre os professores possuem os conhecimentos necessários para identificarem as situaçóes de bullying que ocorrem em sua presença e/ou estão preparados para intervirem nestas situaçôes (SILVA et al., 2017; SMITH; SHU, 2000). Âs vezes, não se encontram suficientemente sensibilizados ao bullying, tendendo a banalizar as agressôes, considerando-as como brincadeiras típicas da infância e da adolescência (PŠUNDER, 2010). Diante este cenário, denota-se a importância de na formação inicial e continuada do professor a temática bullying ser incluída, de modo a incrementar não somente seu conhecimento, mas, principalmente, sua sensibilidade e sua competência para identificar e intervir no problema, contribuindo assim para que o clima escolar seja menos violento e excludente. O presente estudo objetiva apresentar um panorama das produçóes nacionais e internacionais a respeito do papel desempenhado pelos professores e as implicaçóes deste nos processos de prevenção, identificação e intervenção no bullying. 


\section{Conhecimentos dos professores sobre bullying}

Uma característica pessoal dos professores que influencia sua capacidade para identificar e lidar adequadamente com as situaçóes de bullying, em sala de aula, diz respeito à formação que têm sobre o tema, especificamente ao nível dos conhecimentos adquiridos acerca de suas principais características, formas de intervenção, entre outros aspectos de natureza teórica/conceitual. No estudo de Silva et al. (2014), com professores brasileiros, verificou-se que os investigados possuíam conhecimentos gerais acerca do bullying, em sua maioria incompletos ou fragmentados. Embora o nível de conhecimento tenha variado, em termos de abrangência e de profundidade, este não era, de modo geral, suficiente para que eles identificassem a maioria das agressôes ocorridas em sala de aula. Dentro disso, as intervençôes que realizavam eram pontuais e desarticuladas.

O estudo desenvolvido por Silva et al. (2017), sobre a consciência dos professores em relação aos processos de produção e de redução do bullying, apresentou resultados semelhantes. As respostas dos professores apresentaram variações, denotando que alguns possuíam maior consciência e domínio teórico acerca da produção e das formas de enfrentamento do bullying e outros apresentavam consciência limitada. As propostas de intervenção sugeridas pelos professores que apresentavam maior consciência eram mais estruturadas e abrangentes, ao passo que as intervençôes sugeridas por aqueles que apresentaram consciência limitada atrelavam-se a propostas essencialmente punitivas ou à não-intervenção. É importante destacar que a aplicação de punições muito rígidas às crianças/adolescentes contribui para a desvinculação escolar e, embora possam gerar efeito positivo, a curto prazo, em termos de controle disciplinar, a longo prazo, aumentam os problemas disciplinares e o bullying (SILVA; BAZON, 2014).

Apesar de muitas vezes os professores não possuírem conhecimentos aprofundados e abrangentes em relação ao bullying, existem indicações de que eles tendem a superestimar suas habilidades de identificação, bem como sua competência para intervir eficazmente (HEKTNER; SWENSON, 2012). Isto é preocupante, pois eles, geralmente, relatam a ocorrência de um número significativamente menor de agressóes, em comparação ao que relatam os estudantes. Por exemplo, no estudo de Bradshaw, Sawyer e O'Brennan (2007), levando em conta as informaçôes oferecidas pelos estudantes, a prevalência estimada de vítimas frequentes de bullying, na escola, seria de 33\%. Com base em informaçóes oferecidas por $70 \%$ dos professores, a prevalência estimada seria menor que $10 \%$. Em direção semelhante, no estudo de Yahaya et al. (2009), a taxa global de bullying identificada pelos professores investigados foi classificada em nível baixo, enquanto a identificada pelos estudantes foi classificada em nível moderado. Trevisol e Campos (2016), por sua vez, em estudo nacional, identificaram que metade dos professores participantes da pesquisa, surpreendentemente, relatou não haver bullying nas escolas em que lecionavam, o que parece pouco verossímil.

A falta de conhecimento consistente atrela-se, assim, a um baixo nível de eficácia para identificar e manejar adequadamente as situaçóes de bullying na escola, 
lembrando que intervençôes ineficazes em geral agravam as agressóes em curso. A esse respeito, é interessante destacar alguns estudos. Smith e Shu (2000) identificaram que aproximadamente metade das crianças relatou que contar sobre a vitimização sofrida a um professor não melhorou o problema. No estudo de Bradshaw, Sawyer e O'Brennan (2007) se verificou que 52\% dos estudantes relataram ter observado os adultos da escola ignorando o bullying e que $62 \%$ relataram que os professores, quando agiam, em geral, pioravam as agressôes. Essa situação, sem dúvida, impacta as possibilidades de fomentar, na escola, pedidos de ajuda por parte das vítimas, pois dificilmente esses estudantes relatarão sua condiçáo a um professor que ele considere que irá ignorar ou que intervirá de uma forma inadequada, a ponto de piorar a vitimização sofrida. A noção clara sobre os limites e as formas possíveis de intervenção é importante e pode ser obtida mediante formação (SILVA et al., 2017).

\section{Crenças dos professores sobre bullying}

Para além dos conhecimentos que os professores possam ter acerca do bullying, as crenças que possuem sobre o fenômeno remetem a outra importante característica pessoal que influencia a sua capacidade de identificação e os modos como realizam as intervençôes. Kochenderfer-Ladd e Pelletier (2008), por exemplo, identificaram que os professores apresentam a crença de que o bullying constitui um comportamento normativo e a de que os estudantes devem se autodefender (revidando a agressão ou evitando o agressor). Mediante tais crenças, eram menos propensos a intervirem nas situaçóes presenciadas. Resultados semelhantes foram identificados por TroopGordon e Ladd (2015). Eles verificaram que os professores que apresentam crenças normativas sobre o bullying, no sentido de que ele é um acontecimento que faz parte das interaçóes humanas e, mais ainda, que ajuda na aprendizagem de normas sociais, tendiam a acreditar que os estudantes não seriam intimidados/agredidos se se defendessem das agressóes ou se evitassem o contato com os agressores. Do mesmo modo, Silva et al. (2014) também identificaram que os professores que possuíam crenças normativas concebiam o bullying como sendo um acontecimento não muito grave e consideravam as agressôes como comportamentos característicos/inerentes ao processo de socialização entre crianças e adolescentes, no ambiente escolar, devendo, por isso, ser solucionado pelos próprios estudantes.

Esta tendência à naturalização das agressóes é problemática por isentar os professores da responsabilidade de se implicarem de forma intencional e planejada na prevenção e no enfrentamento do bullying, sobretudo aquele que ocorre em sala de aula. A falta de intervenção por parte dos professores, conforme já mencionado, pode influenciar negativamente o comportamento dos estudantes, pois transmite ou reforça a mensagem de que a violência na sala de aula é tolerada ou até mesmo permitida (HEKTNER; SWENSON, 2012). Por sua vez, a crença de que as vítimas podem/ devem se defender reforça a ideia de que, de algum modo, elas são responsáveis pelas agressóes que sofrem, conforme aponta o estudo de Silva et al. (2017), sendo que tal ideia também fomenta um contexto propício à revitimização dos estudantes.

É preciso salientar que, além dessas crenças gerais a respeito do bullying, as concepçôes sobre as diferentes formas de agressão que lhes são inerentes também 
orientam o modo como os professores identificam, interpretam e respondem às situaçóes que presenciam em sala de aula. As agressóes físicas, por exemplo, por ocasionarem lesôes corporais visíveis, são consideradas mais graves pelos professores e, por essa razão, estes tendem a agir de forma imediata e severa frente a esta modalidade (SILVA et al., 2013; YOON; SULKOWSKI; BAUMAN, 2016). Nesta direção, um estudo realizado com estudantes de licenciaturas revelou que os futuros professores propunham intervençôes mais severas para a agressão física e sentiam mais empatia pelas vítimas desse tipo de agressão (BAUMAN; DEL RIO, 2006). Em contrapartida, as agressôes verbais e relacionais não são consideradas graves. Conforme já mencionado, percebem-nas como brincadeiras inofensivas, típicas da infância e da adolescência. Assim, os professores tendem ignorá-las ou a tolerá-las, acreditando que os próprios estudantes podem resolver os seus conflitos (PŠUNDER, 2010; YOON; KERBER, 2003).

O gênero do aluno, assim como o do professor, também parece exercer influência nas respostas dos professores às diferentes formas de agressão no bullying. Por exemplo, no estudo de Kahn, Jones e Wieland (2012), identificou-se que os professores investigados não consideram necessária intervenção diante de agressão relacional entre os estudantes do sexo masculino, mesmo reconhecendo-a como grave. De forma geral, os professores tendem a considerar o bullying como uma situação menos grave quando envolve meninos, e a esperar que eles resolvam por si mesmos este tipo de situação (TROOP-GORDON; LADD, 2015). Quanto ao gênero do professor, há indicativos de que as professoras, de forma geral, classificam o bullying entre estudantes como sendo mais graves, em comparação aos professores (sexo masculino) (GREEN; SHRIBERG; FARBER, 2008). As razóes para isso têm certamente a ver com concepçóes relativas ao que se considera próprio a cada gênero, mas precisam ser melhor investigadas.

Fato é que, como as consequências do bullying são quase sempre muito negativas, independentemente do tipo de agressão e do sexo dos envolvidos, os professores, sejam eles homens ou mulheres, necessitam estar conscientes e sensibilizados em relação à problemática. Dentro disso, é fundamental que encarem as agressóes verbal e relacional como violência grave, até porque são as formas predominantes de bullying, na adolescência, uma vez que agressóes físicas se tornam menos toleráveis tanto pelos estudantes quanto pelas autoridades escolares, tendendo a diminuir com a idade (JUVONEN; GRAHAM, 2014). Destaca-se, cada vez mais, que as crianças e os adolescentes vítimas, na maioria das vezes, não possuem as condições para darem fim à violência que sofrem, qualquer que seja a forma por ela assumida. Eles precisam de auxílio, pois se encontram em relação assimétrica com o agressor que possui mais poder físico, psicológico e/ou social (SILVA et al., 2016).

Ademais, é preciso sublinhar que a experiência dos próprios professores com bullying, em sua história, como estudantes, conecta-se às crenças têm e ao modo como agem em relaçáo ao fenômeno. Twemlow et al. (2006) constataram que a experiência de vitimização dos professores os predispóe a intervirem mais, tanto com as vítimas quanto com os agressores. Kokko e Porhola (2009), em seu turno, identifica- 
ram que professores que sofreram bullying apresentam maior empatia pelos estudantes vítimas e se sentem mais confiantes para abordarem-nos e orientá-los.

Em contraste, segundo Oldenburg et al. (2015), as salas de aulas de professores que relatam terem sido agressores, quando estudantes, apresentam maior frequência de agressóes, em comparação com as salas de aula de professores que não foram agressores. Isto, talvez, se deva ao fato de esses professores não considerarem as agressôes praticadas em sala de aula como um problema. Em função disso, eles seriam menos inclinados a manejarem o bullying entre os seus alunos.

Já os professores que relatam terem sido testemunhas de bullying, ao longo de sua vida escolar, se mostram sensíveis às situaçóes, porém mais propensos a envolver outros profissionais nas intervençóes com as vítimas, que agir por si mesmos (KAHN; JONES; WIELAND, 2012). Tenderiam a perceber as situaçôes, mas não a interferir direta e pessoalmente nelas.

Independentemente do sexo e do histórico pessoal, relativo ao bullying, as crenças que os professores possuem a respeito de seu papel de educador têm maior impacto no modo como eles percebem e lidam com as questóes/problemas dos estudantes (ROESER; MIDGELY, 1997). Os professores que possuem a crença de que garantir o bem-estar dos alunos constitui-se em uma atribuição da sua profissão se mostram, em geral, mais engajados e responsivos em relação a situaçóes que transcendem a prática pedagógica, mas que igualmente impactam a qualidade da trajetória educacional dos estudantes, como as situaçóes de violência, por exemplo (YOON; SULKOWSKI; BAUMAN, 2016).

É claro que as crenças dos professores vão se construindo e se modificando com as experiências e, dentro disto, podem se relacionar também às experiências prévias de ação frente ao bullying (ou seja, às intervençóes que realizaram). Se, ao agirem em determinada situação, se perceberem como bem sucedidos, desenvolvem um senso de autoeficácia, no sentido de se sentirem preparados e capazes de se posicionarem diante das agressóes em situaçôes futuras. O contrário, se se perceberem como mal sucedidos, a tendência seria deixar de agir, uma vez que a intervenção em violência exige, além de conhecimentos específicos, uma disposição pessoal para se envolver nestas situaçóes (SILVA et al., 2017).

Como as crenças dos professores subsidiam suas ações ou suas não-ações diante do bullying, assim como as suas experiências presentes e passadas, é importante que intervençóes antibullying considerem as características pessoais dos professores, no sentido de fortalecer os mais inseguros e sensibilizar os mais alheios às agressóes e às vítimas, além de capacitar a todos, indistintamente, no tocante às estratégias de prevenção e de intervençáo apropriadas/efetivas. As crenças e as percepçóes podem ser alteradas/ajustadas mediante formaçáo, com a aquisição de conhecimentos sobre como identificar e como intervir adequadamente, o que pode, por sua vez, propiciar o senso de autoeficácia em relaçáo ao enfrentamento do fenômeno em sala de aula e na escola (TROOP-GORDON; LADD, 2015). Obviamente, os professores também precisam ser formados no tocante ao papel que exercem, entendendo que a 
escola compóe o sistema de promoção e de proteção da infância e da adolescência e que a educação, assim, implica açôes que transcendem a transmissão de conteúdos.

\section{As ações dos professores frente ao bullying}

Primeiramente, é preciso destacar que o bom relacionamento entre professores e estudantes é apontado como um elemento chave para uma baixa prevalência de bullying em sala de aula (STASIO; SAVAGE; BURGOS, 2016; WANG et al., 2015). Esse bom relacionamento é mais facilmente alcançado nos primeiros anos do Ensino Fundamental, quando há somente um professor por turma. A partir do sexto ano, quando o tempo total das aulas é distribuído entre vários professores, a vinculação fica mais frágil, sendo que neste período verifica-se um aumento na prevalência geral de bullying (SILVA et al., 2016; WANG et al., 2015).

É interessante notar, conforme indicam Konishi et al. (2010), que a percepção dos estudantes quanto à imparcialidade dos professores, no tocante à atenção que dispensavam à turma como um todo, e quanto à sua vontade em ajudar os alunos, associa-se a uma interação professor-aluno valorada positivamente, sendo que esta modera os efeitos negativos que a experiência do bullying, na escola, possa ter no desempenho escolar. Portanto, ao proporcionarem uma interação baseada no respeito e na consideração pelas dificuldades escolares e relacionais apresentadas pelos estudantes, os professores criam condiçóes para se estabelecer, em sala de aula, um contexto de respeito e de segurança, com pouca ou nenhuma violência. Contrariamente, como destacam Shin e Hye (2008), o bullying é mais frequente em salas de aula em que os professores se mostram mais distantes, menos interessados na vida escolar dos estudantes, ou, na pior das hipóteses, em salas de aulas marcadas por conflitos entre professores e alunos. Esses autores verificaram que as crianças/adolescentes vitimizadas por bullying relatam, na maior parte das vezes, pouca proximidade com seus professores e, por vezes, conflitos com eles, o que, talvez, incremente o isolamento destes alunos e retroalimente as agressóes das quais são alvo.

É certo que os professores constituem-se em modelos de comportamento social, ou seja, o modo como eles se posicionam diante de diversas situaçóes em sala de aula, incluindo as de bullying, influencia os estudantes acerca das formas de interagir entre si e sobre como devem se posicionar diante de agressóes praticadas contra seus pares (SILVA et al., 2013). Desse ponto de vista, as relaçóes estabelecidas em sala de aula são fundamentais à compreensão da dinâmica de ocorrência do bullying (SWEARER; ESPELAGE, 2001). Roland e Galloway (2002) verificaram que as salas de aula caracterizadas por relaçôes mais coesas, amigáveis e solidárias, também se caracterizam por uma menor ocorrência de agressôes. Esta associação tem sido evidenciada por dados de outros estudos (CHOI; JOHNSON; JOHNSON, 2011; WOOLFOLK-HOY; WEINSTEIN, 2006).

Tratando especificamente de açôes/intervençôes realizadas por professores focalizando o bullying, é preciso dizer, primeiramente, que não há muitas pesquisas a este respeito (SOKOL; BUSSEY; RAPEE, 2016). O levantamento realizado identificou poucas investigaçóes em que este foi o objeto. Em âmbito internacional, o estudo 
feito por Nicolaides; Toda e Smith (2002), por exemplo, mostrou que a ação mais comum aos professores era orientar/aconselhar as vítimas, recomendando que elas "se afastem dos agressores, calmamente" e/ou que "digam aos agressores para pararem" el ou "peçam ajuda aos amigos". Já na investigação de Sokol, Bussey e Rapee (2016), os professores se mostraram mais propensos a aconselhar as vítimas a relatar o bullying à equipe escolar e a "ignorar o agressor", indicando-lhes que esta seria uma das reaçóes mais eficazes para interromper as agressôes.

Segundo Troop-Gordon e Ladd (2015), a literatura internacional, especialmente aquela produzida nos Estados Unidos, converge nos apontamentos de que os professores tendem a intervir em situaçôes de bullying aconselhando as vítimas a se autodefenderem e/ou a evitarem os agressores e, na melhor das hipóteses, a pedirem ajuda a outros profissionais da escola, como os diretores. Estas açôes certamente refletem o nível dos conhecimentos e as crenças que têm os professores a respeito do fenômeno. À exceção do pedido de ajuda a adultos, as demais ações são pouco efetivas porque há variaçôes nas habilidades das crianças/adolescentes para manterem a calma e/ou para se posicionarem diante do agressor.

No contexto brasileiro, os professores investigados por Silva et al. (2013), quando solicitados a indicarem as intervençôes que realizam em relação ao bullying, reportaram as seguintes açóes: divulgar as regras escolares (contrárias ou, mesmo, proibitivas do bullying), discutir em grupo as agressóes presenciadas, exigir que os agressores pesquisem e apresentem o tema em sala de aula, encaminhar os agressores à direção da escola e comunicar aos seus pais/responsáveis. Alguns ainda indicaram que a ação adequada seria ignorar as situaçôes, de modo a não reforça-las.

É certo que a divulgação das regras escolares cujo conteúdo seja contraditório à expressão de violência é importante, pois assim se estabelecem diretrizes claras à conduta dos estudantes. Entretanto, a simples divulgação não é suficiente para que os alunos as legitimem, tomando-as para si. Além disso, é fundamental que o respeito às regras seja uniformemente cobrado pelas autoridades escolares, sempre que necessário, a todos indistintamente, de modo que os estudantes não experienciem lacunas ou contradiçôes (SILVA; BAZON, 2014). Com relação às discussôes envolvendo toda a turma, a ação é, em princípio positiva, pois revela que o professor compreende que o bullying é um fenômeno de grupo, influenciado pelas reaçóes dos pares que podem tanto incentivar as agressôes quanto inibi-las ao defenderem as vítimas (SWEARER; ESPELAGE, 2001). Todavia, essa ação requer que o professor possua conhecimentos mais amplos sobre os fenômenos grupais e sobre o bullying em si, de modo que consiga criar as condiçốes efetivas para que os alunos se conscientizem e se sensibilizem à natureza prejudicial das agressôes e à responsabilidade de todos no tocante à qualidade das interaçóes, intervindo sempre que necessário e de forma correta. No que concerne ao encaminhamento dos agressores à direção da escola, o recomendável é que esta ação se dê em continuidade aos esforços já realizados pelos professores em sala de aula, para que os estudantes percebam que todos os níveis de organização da escola estão trabalhando em conjunto e sobre os mesmos princípios. Assim, torna-se claro para eles que os seus atos serão sempre suscetíveis a alguma consequência disciplinar, 
sendo que esta certeza de responsabilização é fundamental para que alterem as suas condutas. Essa ação, todavia, não pode ser muito rígida (e tampouco vexatória), uma vez que puniçôes muito severas tem o efeito de fragilizar a vinculaçáo escolar e assim diminuir o impacto positivo que a coerção social pode ter (SILVA; BAZON, 2014). Quanto à comunicaçáo aos pais/responsáveis, esta pode ser considerada uma ação adequada se for complementar a outras mais abrangentes e de caráter mais educativo. A autoridade familiar é importante à socializaçáo de crianças e adolescentes, mas seu exercício é limitado, em se tratando dos eventos que se processam na escola, no interior das salas de aula. Ademais, é fundamental considerar que os pais/responsáveis são em grande parte leigos em relação ao bullying, o que pode concorrer para que ajam de forma limitada, senão inadequada, junto aos filhos (OLIVEIRA et al., 2015). Por fim, o apontamento referente à omissão dos professores frente ao bullying é, de todas as açôes, a única que não tem lado positivo. Conforme o já mencionado, ignorar as agressôes praticadas em sala de aula transmite a mensagem de que a violência é tolerada, senão permitida. A esse respeito, os próprios estudantes consideram que uma das melhores estratégias para prevenir e reduzir o bullying escolar é uma gestão eficaz das aulas pelos professores (CROTHERS; KOLBERT; BARKER, 2006). Perceber que o professor se importa com a qualidade das interaçôes em sala de aula, que ele quer ajudar e, mais, que é coerente na aplicação das regras escolares, tem importante impacto nas chances de vitimização, além de exercer efeito de proteção (KONISHI et al., 2010).

Apesar da potencialidade da maior parte das açóes reportadas pelos professores investigados no estudo de Silva et al. (2013), é preciso considerar que todas remetem a intervençôes pontuais, cujos efeitos positivos, se houver, são bastante restritos, denotando que eles não possuem o conhecimento necessário à compreensão do fenômeno bullying, em toda a sua complexidade, não estando, portanto, preparados para abordá-lo eficazmente, levando em conta o contexto das interaçóes e das agressóes, bem como as características dos estudantes envolvidos.

Uma situação diferenciada foi identificada na investigação de Sokol, Bussey e Rapee (2016). Nesta, um terço dos professores participantes reportaram orientar as intervençôes que realizavam de acordo com cada situação, considerando o tipo de agressáo praticada, as características pessoais dos estudantes envolvidos e as possibilidades de o agressor culpar a vítima e querer se "vingar" no futuro. Nessa mesma direçáo, Silva e Rosa (2013) também verificaram que alguns dos professores pesquisados indicaram como intervençáo adequada uma sequência de açóes, articuladas entre si, denotando uma visão de complexidade maior. Segundo esses autores, os professores diziam ser sempre importante averiguar o ocorrido, dialogar com os estudantes envolvidos e, se necessário, solicitar auxílio da direção da escola e/ou a outras autoridades do sistema de proteção à infância e à adolescência. Igualmente, uma pequena parcela dos professores do estudo de Silva et al. (2017) também apresentou uma compreensão mais ampla e aprofundada acerca do bullying, propondo açóes bem estruturadas e articuladas. Esses dados indicam que é possível que as campanhas e as formaçôes em bullying, que se sucedem, também de forma pontual, podem estar começando a ter os primeiros desdobramentos, propiciando a existência de alguns 
professores mais sensíveis e melhor preparados para assumirem o papel que lhes é devido na rede de promoção e proteção da infância e juventude.

\section{Considerações finais}

As diversas investigaçóes apresentadas e discutidas neste estudo permitem obter uma visão geral do papel dos professores e suas implicaçóes nos processos de produçáo, prevenção e redução do bullying. Ficou evidenciado que os conhecimentos, as crenças e as experiências pessoais deles em relação ao bullying influenciam positiva ou negativamente o modo como compreendem, identificam e lidam com esse fenômeno em sala de aula. Como todos os aspectos problemáticos na atuação dos professores frente a esta problemática são suscetíveis de alteração, ressalta-se a importância de receberem formação específica (seja no âmbito da formação inicial, seja no da continuada), de modo a incrementar não somente o conhecimento sobre o tema, mas, principalmente, a sensibilidade e a competência para intervir no problema, contribuindo assim para que o clima escolar seja mais favorável à aprendizagem e às interaçóes e, assim, menos violento e excludente.

\section{Referências}

BAUMAN, S.; DEL RIO, A. Preservice teachers' responses to bullying scenarios: comparing physical, verbal, and relational bullying. Journal of Educational Psychology, Arlington, v. 98, n. 1, p. 219-231, Feb. 2006.

BRADSHAW, C. P.; SAWYER, A. L.; O'BRENNAN, L. M. Bullying and peer victimization at school: perceptual differences between students and school staff. School Psychology Review, Cuyahoga, v. 36, n. 3, p. 361-382, Jan. 2007.

CHOI, J.; JOHNSON, D. W.; JOHNSON, R. Relationship among cooperative learning experiences, social interdependence, children aggression, victimization, and prosocial behaviors. Journal of Applied Social Psychology, Silver Spring, v. 41, n. 4, p. 976-1003, Abr. 2011.

CROTHERS, L. M.; KOLBERT, J. B.; BARKER, W. F. Middle school students' preferences for anti-bullying interventions. School Psychology International, London, v. 27, n. 4, p. 475-487, Aug. 2006.

DUE, P. et al. Socioeconomic inequality in exposure to bullying during adolescence: a comparative, crosssectional, multilevel study in 35 countries. American Journal of Public Health, United States, v. 99, n. 5, p. 907-914, May. 2009.

GREEN, S.; SHRIBERG, D.; FARBER, S. What's gender got to do with it? teachers' perceptions of situation severity and requests for assistance. Journal of Educational and Psychological Consultation, Hillsdale, v. 18, n. 4, p. 346-373, nov. 2008.

HEKTNER, J. M.; SWENSON, C. A. Links from teacher beliefs to peer victimization and bystander intervention tests of mediating processes. The Journal of Early Adolescence, Berlin, v. 32, n. 4, p. 516-536, Aug. 2012.

JUVONEN, J.; GRAHAM, S. Bullying in schools: the power of bullies and the plight of victims. Annual Review of Psychology, Palo Alto, v. 65, p. 159-185, Aug. 2014.

KAHN, J. H.; JONES, J. L.; WIELAND, A. L. Preservice teachers' coping styles and their responses to bullying. Psychology in the Schools, Brandon, v. 49, n. 8, p. 784-793, Sep. 2012.

KOCHENDERFER-LADD, B.; PELLETIER, M. E. Teachers' views and beliefs about bullying: influences on classroom management strategies and students' coping with peer victimization. Journal of School Psychology, New York, v. 46, n. 4, p. 431-453, Aug. 2008.

KOKKO, T. H.; PORHOLA, M. Tackling bullying: victimized by peers as a pupil, an effective intervener as a teacher? Teaching and Teacher Education, New York, v. 25, n. 8, p. 1000-1008, Nov. 2009.

KONISHI, C. et al. Do school bullying and student-teacher relationships matter for academic achievement? a multilevel analysis. Canadian Journal School Psychology, v. 25, n. 1, p. 19-39, 2010.

NICOLAIDES, S.; TODA, Y.; SMITH, P. K. Knowledge and attitudes about school bullying in trainee teachers. British Journal of Educational Psychology, Leicester, v. 72, n. 1, p. 105-118, Mar. 2002. 
OLDENBURG, B. et al. Teacher characteristics and peer victimization in elementary schools: a classroom-level perspective. Journal of Abnormal Child Psychology, New York, v. 43, n. 1, p. 33-44, jan. 2015.

OLIVEIRA, W.A. et al. Associations between the practice of bullying and contextual variables from the aggressors' perspective. Jornal de Pediatria, Porto Alegre, v. 92, n. 1, p. 32-39, jan./fev. 2016.

OLIVEIRA, W. A. et al. Interfaces entre família e bullying escolar: uma revisão sistemática. Psico-USF, Bragança Paulista, v. 20, n. 1, p. 121-132, jan./abr. 2015.

OLWEUS, D. School bullying: development and some important challenges. Annual Review of Clinical Psychology, Pato Alto, v. 9, p. 751-780, Jan. 2013.

PŠUNDER, M. The identification of teasing among students as an indispensable step towards reducing verbal aggression in schools. Educational Studies, Oxford, v. 36, n. 2, p. 217-228, May. 2010.

ROESER, R. W.; MIDGLEY, C. Teachers' views of issues involving students' mental health. The Elementary School Journal, Chicago, v. 98, n. 2. p. 115-133, Nov. 1997.

ROLAND, E.; GALLOWAY, D. Classroom influences on bullying. Educational Research, Oxfordshire, v. 44, n. 3, p. 299-312, Dec. 2002.

SAMPAIO, J. M. C. et al. Prevalência de bullying e emoçôes de estudantes envolvidos. Texto \& Contexto Enfermagem, Florianópolis, v. 24, n. 2, p. 344-352, abr./jun. 2015.

SHIN, Y.; HYE, Y. K. Peer victimization in Korean preschool children: the effects of child characteristics, parenting behaviors, and teacher-child relationships. School Psychology International, London, v. 29, n. 5, p. 590-605, Oct. 2008.

SILVA, E. N.; ROSA, E. C. S. Professores sabem o que é bullying? um tema para a formação docente. Psicologia Escolar e Educacional, Campinas, n. 17, n. 2, p. 329-338, jul./dez. 2013.

SILVA, J. L. et al. Bullying na sala de aula: percepção e intervenção de professores. Arquivos Brasileiros de Psicologia, Rio de Janeiro, v. 65, n. 1, p. 121-137, jan./jun. 2013.

SILVA, J. L. et al. Bullying: conhecimentos, atitudes e crenças de professores. Psico, Porto Alegre, v. 45, n. 2, p. 147-156, abr./jun. 2014.

SILVA, J. L.; BAZON, M. R. Educação escolar e conduta infracional em adolescentes: revisão integrativa da literatura. Estudos de Psicologia (Natal), Natal, v. 19, n. 4, p. 278-287, out./dez. 2014.

SILVA, J.L. et al. The effects of a skill-based intervention for victims of bullying in Brazil. International Journal of Environmental Research and Public Health, Switzerland, v. 13, n. 10, p. 1042-1052, Oct. 2016.

SILVA, P. F. et al. Limites da consciência de professores a respeito dos processos de produção e redução do bullying. Psicologia USP, São Paulo, v. 28, n. 1, p. 44-56, jan./abr. 2017.

SMITH, P. K.; PEPLER D.; RIGBY, K. Bullying in schools: how successful can interventions be?. Cambridge: Cambridge University Press, 2004.

SMITH, P. K.; SHU, S. What good schools can do about bullying: findings from a decade of research and action. Childhood: a Global Journal of Child Research, London, v. 7, n. 2, p. 193-212, May. 2000.

SOKOL, N.; BUSSEY, K.; RAPEE, R.M. Teachers' perspectives on effective responses to overt bullying. British Educational Research Journal, Oxfordshire, v. 42, n. 5, p. 851-870, Oct. 2016.

STASIO, M. R.; SAVAGE, R.; BURGOS, G. Social comparison, competition and teacherestudent relationships in junior high school classrooms predicts bullying and victimization. Journal of Adolescence, London, v. 53, p. 207-216, Dec. 2016.

SWEARER, S.; ESPELAGE, D. Expanding the social-ecological framework of bullying among youth: lessons learned from the past and directions for the future. In: ESPELAGE, D. L.; SWEARER, S. M. (Org.). Bullying in north american schools. New York: Lawrence Erlbaum, 2001. p. 3-10.

TREVISOL, M. T. C.; CAMPOS, C. A. Bullying: verificando a compreensão dos professores sobre o fenômeno no ambiente escolar. Psicologia Escolar e Educacional, Campinas, v. 20, n. 2, p. 275-283, maio/ago. 2016.

TROOP-GORDON, W.; LADD, G. Teachers' victimization-related beliefs and strategies: Associations with students' aggressive behaviour and peer victimization. Journal of Abnormal Child Psychology, New York, v. 43, n. 1, p. 45-60, Jan. 2015.

TTOFI, M. M.; FARRINGTON, D. P. Effectiveness of school-based programs to reduce bullying: a systematic and meta-analytic review. Journal of Experimental Criminology, v. 7, n. 1, p. 27-56, Mar. 2011. 
TWEMLOW, S. W. et al. Teachers who bully students: a hidden trauma. International Journal of Social Psychiatry, London, v. 2, n. 3, 62, p. 187-198, may. 2006.

WANG, C. et al. Teachers matter: an examination of student-teacher relationships, attitudes toward bullying, and bullying behavior. Journal of Applied School Psychology, v. 31, n. 3, p. 219-238, Aug. 2015.

WOOLFOLK-HOY, A.; WEINSTEIN, C. Student and teacher perspectives on classroom management. In: EVERTSON, C. M.; WEINSTEIN, C. S. (Org.). Handbook of classroom management, research, practice and contemporary issues. Mahwah: Erlbaum, 2006. p. 181-219.

YAHAYA, A. et al. Teachers and students perception towards bullying in Batu Pahat district secondary school. European Journal of Social Sciences, Victoria, v. 11, n. 4, p. 643-658, Nov. 2009.

YOON, J.; SULKOWSKI, M. L.; BAUMAN, S. A. Teachers' responses to bullying incidents: effects of teacher characteristics and contexts. Journal of School Violence, v. 15, n. 1, p. 91-113, Oct. 2016.

YOON, J. S.; KERBER, K. Bullying: elementary teachers' attitudes and intervention strategies. Research in Education, v. 69, n. 1, p. 27-36, May. 2003.

\section{Correspondência}

Marina Rezende Bazon - Universidade de São Paulo, Faculdade de Filosofia Ciências e Letras de Ribeirão Preto, Departamento de Psicologia e Educaçăo. Av. Bandeirantes, 3900. Monte Alegre. CEP: 14040-901. Ribeirao Preto, São Paulo, Brasil.

E-mail: jorgelsilva@usp.br - mbazon@ffclrp.usp.br

Recebido em 11 de julho de 2017

Aprovado em 11 de agosto de 2017 
